\title{
Analisis Kestabilan Transien dan Pelepasan Beban Pada Sistem Integrasi 33 KV PT. Pertamina RU IV Cilacap akibat Penambahan Beban RFCC dan PLBC
}

\author{
Firdaus Ariansyah, Ardyono Priyadi, dan Margo Pujiantara \\ Jurusan Teknik Elektro, Fakultas Teknologi Industri, Institut Teknologi Sepuluh Nopember (ITS) \\ Jl. Arief Rahman Hakim, Surabaya 60111 \\ E-mail: priyadi@ee.its.ac.id, margo@ee.its.ac.id
}

\begin{abstract}
Abstrak - Keseimbangan daya antara kebutuhan beban dengan kapasitas pembangkitan generator merupakan salah satu parameter dari kestabilan operasi sistem tenaga listrik. Namun dalam pengoperasian sistem tenaga listrik akan selalu terjadi perubahan beban sehingga pembangkit perlu menyesuaikan daya keluarannya melalui governor maupun pengaturan eksitasi. Hal ini perlu dilakukan agar kestabilan sistem tetap terjaga. Adanya penambahan beban pada sistem kelistrikan di PT Pertamina RU IV Cilacap mengakibatkan penambahan pembangkit dan pabrik baru. Akibatnya sistem kelistrikan di PT Pertamina RU IV Cilacap berubah karena perlu menambahkan sistem bus $33 \mathrm{kV}$. Untuk mengetahui batas kestabilan yang baik pada sistem kelistrikan suatu industri, maka ditetapkan standar batas kemampuan normal frekuensi, tegangan, dan sudut rotor. Standar yang digunakan mengacu pada IEEE Std C37.106-2003 (Revisi dari ANSI/IEEE C37.106-1987) mengenai pengamanan frekuensi abnormal turbin dengan menggunakan metode pelepasan beban.
\end{abstract}

Kata Kunci: Kestabilan transien, Beban RFCC dan Beban PLBC.

\section{PENDAHULUAN}

Keseimbangan daya antara kebutuhan beban dengan kapasitas pembangkitan generator merupakan salah satu parameter dari kestabilan operasi sistem tenaga listrik. Namun dalam pengoperasian sistem tenaga listrik akan selalu terjadi perubahan beban sehingga pembangkit perlu menyesuaikan daya keluarannya melalui governor maupun pengaturan eksitasi. Hal ini perlu dilakukan agar kestabilan sistem tetap terjaga.

Semakin berkembangnya sistem tenaga listrik di industri maka semakin kompleks pula masalah yang akan dihadapi. Masalah seperti adanya gangguan dari lepasnya generator, gangguan hubung singkat, starting motor ataupun efek dari perubahan beban yg mendadak akan menyebabkan sistem keluar dari daerah kestabilannya. Kecepatan pembangkit memberi reaksi terhadap perubahan yang terjadi pada sistem menjadi faktor penentu dari kestabilan sistem. Kestabilan mesin pembangkit sangat bergantung pada kemapuan sistem kendalinya, dimana sistem kendali dikatakan handal apabila mampu mengendalikan mesin tetap beroperasi dalam keadaan normal dan berada di daerah kestabilannya meskipun sistem mengalami gangguan.

Pada situasi dimana adanya penambahan kapasitas pembangkit dengan daya cukup besar atau beban besar hilang dari sistem atau bahkan terjadi gangguan pada saluran tranmisi, stabilitas sistem harus cukup kuat untuk mempertahankan diri terhadap perubahan beban yang relatif besar, dimana ini akan berdampak pada keseimbangan sistem. Ketidakseimbangan ini akan menyebabkan adanya perubahan pada kestabilan sistem terutama kestabilan frekuensi, kestabilan tegangan dan kestabilan sudut rotor. Karena kestabilan di kelistrikan industri berkaitan dengan kemampuan sistem dalam mempertahankan kondisi kestabilan sehingga peralatan dapat bekerja dengan baik dan memiliki efisiensi tinggi, jadi perlu dilakukan adanya penanganan khusus untuk menjaga sistem tetap dalam keadaan stabil saat terjadi gangguan, salah satunya yaitu mekanisme pelepasan beban atau load shedding.

\section{KESTABILAN TRANSIEN}

Dalam keadaan operasi sistem tenaga listrik yang normal terdapat keseimbangan antara daya mekanis pada prime mover dengan daya listrik atau beban pada sistem. Dalam keadaan seimbang, daya mekanik dan daya elektrik bergerak secara bersamaan dengan kecepatan konstan. Ketika terjadi gangguan, maka terjadi perbedaan daya elektrik dan mekanik dari generator. Kelebihan daya elektrik membuat perlambatan putaran rotor generator, hal ini disebebakan semakin terbebaninya generator. Namun kelebihan daya mekanik membuat percepatan pada putaran rotor, hal ini disebabkan semakin ringan beban yang ditanggung generator. Bila gangguan tidak segera dihilangkan, maka perlambatan atau percepatan putaran rotor generator mengakibatkan hilangnya sinkronisasi dalam suatu sistem [1].

Berdasarkan Paper IEEE definition and classification of power system stability, kestabilan sistem tenaga listrik dibagi menjadi tiga kategori yaitu [2]: 


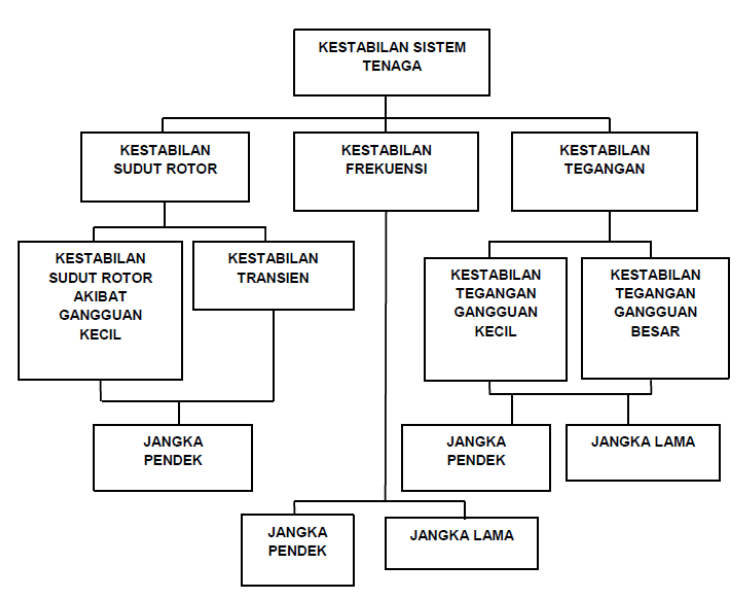

Gambar 1. Klasifikasi Kestabilan Sistem Tenaga

1. Kestabilan sudut rotor

Stabilitas sudut rotor tergantung pada kemampuan untuk mempertahankan atau mengembalikan keseimbangan antara torsi elektromagnetik dan torsi mekanik setiap mesin sinkron dalam sistem tersebut. Ketidakstabilan ini dapat mengakibatkan terjadinya peningkatan ayunan sudut beberapa generator sehingga menyebabkan hilangnya sinkronisasi generator satu dengan generator lain.

2. Kestabilan frekuensi

Kestabilan frekuensi mengacu pada kemampuan sistem untuk tetap mempertahankan nilai frekuensi nominal agar tetap stabil mengikuti perubahan sistem yang berubah secara tiba-tiba akibat ketidakseimbangan pasokan daya pembangkit dengan daya yang diserap beban. Perputaran turbin sangat erat kaitannya dengan frekuensi sistem tenaga listrik.

3. Kestabilan tegangan

Stabilitas tegangan mengacu pada kemampuan suatu sistem tenaga untuk mempertahankan tegangan pada kondisi stabil pada semua bus dalam sistem tenaga listik setelah terjadi gangguan dari kondisi operasi awal yang diberikan. Hal ini tergantung pada kemampuan untuk mempertahankan/mengembalikan keseimbangan antara permintaan beban dan suplai beban dari sistem tenaga listrik. Ketidakstabilan frekuensi dapat mengakibatkan terjadinya penurunan atau naiknya tegangan dari beberapa bus.

Standar yang Digunakan untuk Analisis Kestabilan Transien

Dalam menentukan suatu sistem tenaga listrik stabil atau tidak yaitu dengan mengevaluasi respon tegangan dan frekuensi sistem. Standart yang dipakai untuk menentukan sistem stabil atau tidak yaitu :

Standar Frekuensi yang digunakan adalah standar Untuk Steam Turbin Generator (IEEE Std C37.106-2003)

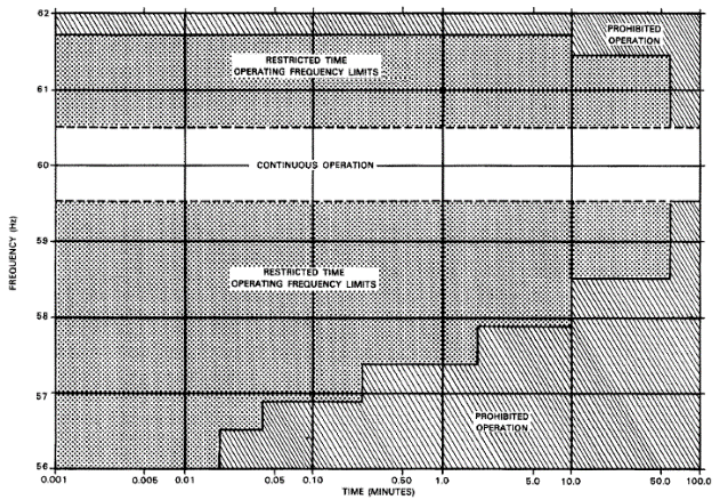

Gambar 2. Standar Frekuensi

Standart tegangan yang digunakan adalah standart IEEE 1159-1995.

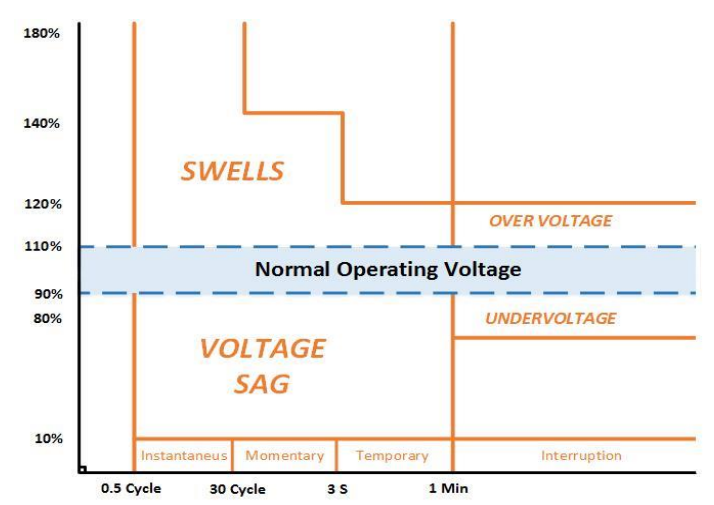

Gambar 3. Standar Tegangan

\section{Pelepasan Beban (Load Shedding)}

Pelepasan beban merupakan salah satu langkah untuk mempertahankan kestabilan. Jika terjadi gangguan seperti generator outage mengakibatkan daya yang tersedia tidak mampu melayani beban, sehingga untuk menjaga sistem tidak black out maka diperlukan pelepasan bebanBerdasarkan standar ANSI/IEEE C37.1061987, terdapat 2 skema pelepasan beban ketika terjadi gangguan antara lain adalah pelepasan beban 3 langkah dan pelepasan beban 6 langkah. Tabel dibawah adalah pelepasan beban 3 langkah di frekuensi $50 \mathrm{~Hz}$ [3]

Tabel 1. Standar Pelepasan Beban 3 Langkah

\begin{tabular}{ccccc}
\hline Step & $\begin{array}{c}\text { Frequency } \\
\text { Trip Point } \\
\text { (Hz) }\end{array}$ & $\begin{array}{c}\text { Percen } \\
\text { (\%) }\end{array}$ & $\begin{array}{c}\text { Percent of } \\
\text { Load } \\
\text { Shedding } \\
\text { (\%) }\end{array}$ & $\begin{array}{c}\text { Fixed Time } \\
\text { Delay } \\
\text { (cycles) } \\
\text { on Relay }\end{array}$ \\
\hline $\mathbf{1}$ & 49,02 & 98,84 & 10 & 6 \\
$\mathbf{2}$ & 49,08 & 98,16 & 15 & 6 \\
$\mathbf{3}$ & 48,75 & 97,5 & $\begin{array}{c}\text { As required to } \\
\text { arrest decline } \\
\text { before 48,5 } \\
\text { Hz }\end{array}$ \\
\hline
\end{tabular}


JURNAL TEKNIK ITS Vol. 5, No. 1, (2016) ISSN: 2337-3539 (2301-9271 Print)

\section{SISTEM KELISTRIKAN}

Sistem kelistrikan PT. Pertamina RU IV Cilacap yang baru dapat ditujukan pada gambar dibawah ini :

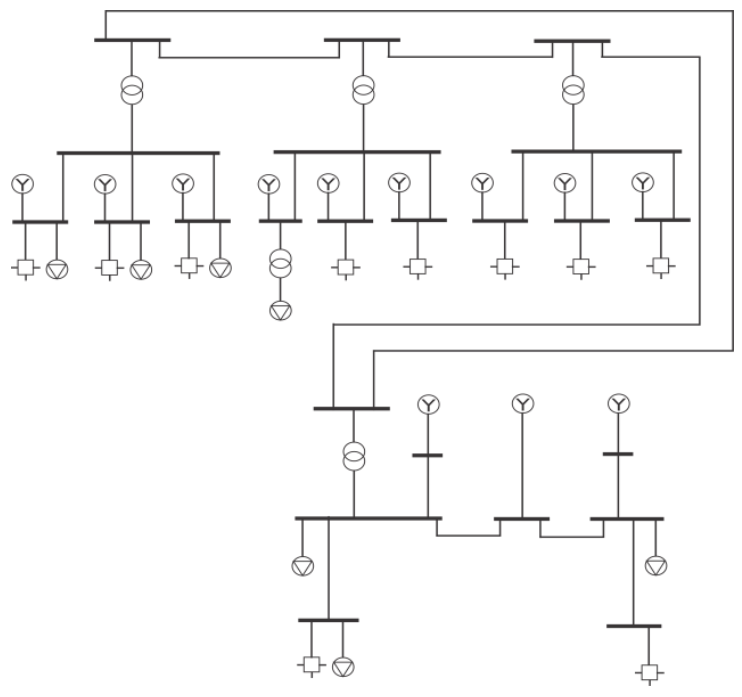

Gambar 4. Single Line Diagram PT. Pertamina RU IV Cilacap

PT. Pertamina Refinery Unit I (Unit Pengolahan) IV Cilacap memiliki sebuah sistem yang cukup besar dengan sistem kelistikan yang juga cukup kompleks. Sebelumnya PT Pertamina RU IV Cilacap memiliki 8 unit pembangkit yang diantaranya terdiri 4 unit berkapasitas $20 \mathrm{MW}$ dan 4 unit pembangkit berkapasitas $8 \mathrm{MW}$. Total Substation di PT. Pertamina RU IV Cilacap berjumlah 32 substation. dimana masing masing substation memiliki beban statis dan motor. Sedangkan untuk sistem kelistrikan di PT. Pertamina RU IV Cilacap dibagi menjadi 3 utility yaitu utility I, II dan IIa.

Adanya penambahan beban pada sistem kelistrikan di PT Pertamina RU IV Cilacap mengakibatkan penambahan pembangkit dan pabrik baru. Akibatnya sistem kelistrikan di PT Pertamina RU IV Cilacap berubah karena perlu menambahkan sistem bus $33 \mathrm{kV}$. Selain itu 3 daerah utility berkembang menjadi 4 daerah utility yaitu tambahan utility III.

Tabel 2.Data Kapasitas Generator

\begin{tabular}{cccccc}
\hline No & ID & MW & MVA & KV & PF \\
\hline $\mathbf{1}$ & $51 G 1$ & 8 & 10 & 13,8 & $80 \%$ \\
$\mathbf{2}$ & $51 G 2$ & 8 & 10 & 13,8 & $80 \%$ \\
$\mathbf{3}$ & $51 G 3$ & 8 & 10 & 13,8 & $80 \%$ \\
$\mathbf{4}$ & $510 \mathrm{G} 2$ & 8 & 10 & 13,8 & $80 \%$ \\
$\mathbf{5}$ & $510 \mathrm{G} 301$ & 8 & 10 & 13,8 & $80 \%$ \\
$\mathbf{6}$ & $510 \mathrm{G} 201$ & 20 & 25 & 13,8 & $80 \%$ \\
$\mathbf{7}$ & $051 \mathrm{G} 101$ & 20 & 25 & 13,8 & $80 \%$ \\
$\mathbf{8}$ & $051 \mathrm{G} 102$ & 20 & 25 & 13,8 & $80 \%$ \\
$\mathbf{9}$ & $051 \mathrm{G} 103$ & 20 & 25 & 13,8 & $80 \%$ \\
$\mathbf{1 0}$ & $152 \mathrm{G} 501 \mathrm{~A}$ & 15 & 18,75 & 13,8 & $80 \%$ \\
$\mathbf{1 1}$ & $152 \mathrm{G} 501 \mathrm{~B}$ & 15 & 18,75 & 13,8 & $80 \%$ \\
\hline
\end{tabular}

\begin{tabular}{llllll}
\hline $\mathbf{1 2}$ & $152 \mathrm{G} 501 \mathrm{C}$ & 15 & 18,75 & 13,8 & $80 \%$ \\
\hline
\end{tabular}

Akibat dari penambahan beban pada sistem kelistrikan di PT. Pertamina RU IV Cilacap mengakibatkan perlunya penambahan pembangkit dan pabrik baru. Penambahan tersebut juga mengakibatkan berubahnya sistem kelistrikan dengan adanya penambahan sistem bus $33 \mathrm{Kv}$ dan berkembangnya daerah utility menjadi 4 daerah utility.

Tabel 3.Data Motor

\begin{tabular}{ccccccc}
\hline No & Motor ID & KV & HP & KVA & RPM & Poles \\
\hline $\mathbf{1}$ & 260K101AM & 3,3 & 2700 & 2612 & 300 & 20 \\
$\mathbf{2}$ & 84K202C & 3,3 & 2000 & 1965 & 300 & 20 \\
$\mathbf{3}$ & 053P101CM & 3,3 & 1250 & 1076 & 1500 & 4 \\
$\mathbf{4}$ & 011P102AM & 3,3 & 1500 & 1289 & 1500 & 4 \\
$\mathbf{5}$ & 014K102ABCM & 3,3 & 2500 & 2437 & 250 & 24 \\
$\mathbf{6}$ & 46P101AM. & 3,3 & 1000 & 910 & 3000 & 2 \\
\hline
\end{tabular}

Beban PLBC atau Proyek Langit Biru Cilacap merupakan penambahan beban baru yang dilakukan di PT Pertamina RU IV Cilacap. Hal ini berkaitan dengan adanya varian baru dari produksi PT pertamina yaitu pertalite. Beban PLBC tersebar di semua utility PT Pertamina RU IV Cilacap. Data beban PLBC dapat dilihat pada data berikut :

Tabel 3.Data Beban PLBC

\begin{tabular}{clccc}
\hline No & \multicolumn{1}{c}{ ID } & KV & KVA & PF \\
\hline $\mathbf{1}$ & PLBC-2_3650HP & 13,8 & 2758 & $98,73 \%$ \\
$\mathbf{2}$ & PLBC-3_200kW2 & 13,8 & 219 & $91,19 \%$ \\
$\mathbf{3}$ & PLBC-2_3650HP1 & 13,8 & 2758 & $98,73 \%$ \\
$\mathbf{4}$ & PLBC-149HP & 13,8 & 174 & $85,6 \%$ \\
$\mathbf{5}$ & PLBC-630HP & 13,8 & 586 & $80,2 \%$ \\
$\mathbf{6}$ & PLBC-149HP1 & 13,8 & 174 & $85,6 \%$ \\
$\mathbf{7}$ & PLBC-630HP2 & 13,8 & 586 & $80,2 \%$ \\
$\mathbf{8}$ & PLBC-3_200kW & 13,8 & 219 & $91,19 \%$ \\
$\mathbf{9}$ & PLBC-1 & 13,8 & 11690 & $74,92 \%$ \\
$\mathbf{1 0}$ & PLBC-630HP1 & 13,8 & 5000 & $80 \%$ \\
\hline
\end{tabular}

\section{SIMULASI DAN ANALISIS TRANSIEN}

Pemodelan Single Line Diagram PT Pertamina RU IV Cilacap dimodelkan melalui software ETAP 12.6 dengan menggunakan datadata existing dan data peralatan yang digunakan di PT Pertamina RU IV Cilacap. Kemudian simulasi akan dilakukan berkaitan dengan analisis kestabilan sistem ketika mengalami gangguan-gangguan besar seperti generator lepas (generator outage) dan starting motor.

\section{Simulasi Kestabilan Transien Generator Lepas}

Pada kasus generator lepas dari sistem kelistrikan, diasumsikan bahwa terdapat satu generator trip secara tiba-tiba setelah sistem beroperasi selama 1 detik. Generator yang lepas untuk Case A adalah GEN 51G2 (8 MW), Case B adalah GEN 152-G-501A (15 MW), dan Case C 
JURNAL TEKNIK ITS Vol. 5, No. 1, (2016) ISSN: 2337-3539 (2301-9271 Print)

adalah GEN 051G-102 (20 MW) dengan kondisi operasi yang berbeda-beda

Tabel 4. Hasil Simulasi Studi Kasus Generator Lepas Menggunakan Load Shedding standar IEEE

\begin{tabular}{|c|c|c|c|c|c|c|c|c|}
\hline \multirow{2}{*}{\multicolumn{2}{|c|}{ Studi kasus }} & \multicolumn{2}{|c|}{$\begin{array}{c}\text { Frekuensi min } \\
(\%)\end{array}$} & \multicolumn{2}{|c|}{$\begin{array}{c}\text { Tegangan min } \\
(\%)\end{array}$} & \multicolumn{2}{|c|}{ kondisi } & \multirow[t]{2}{*}{ Load shedding } \\
\hline & & $33 \mathrm{kv}$ & $13,8 \mathrm{kv}$ & $33 \mathrm{kv}$ & $13,8 \mathrm{kv}$ & $\mathrm{f}$ & $\mathrm{V}$ & \\
\hline \multirow{2}{*}{ TS 1} & A & 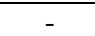 & 99,9 & 96,7 & 96,4 & $\sqrt{ }$ & $\sqrt{ }$ & No Load Shedding \\
\hline & $\mathrm{C}$ & 98,7 & 98,7 & 95,9 & 97,6 & $\sqrt{ }$ & $\sqrt{ }$ & Load Shedding I \\
\hline \multirow{3}{*}{ TS 2} & A & 99,7 & 99,7 & 96,3 & 99,7 & $\sqrt{ }$ & $\sqrt{ }$ & No Load Shedding \\
\hline & B & 98,7 & 98,7 & 95,7 & 91,9 & $\sqrt{ }$ & $\sqrt{ }$ & Load Shedding I \\
\hline & $\mathrm{C}$ & 98,8 & 98,8 & 97,7 & 96,6 & $\sqrt{ }$ & $\sqrt{ }$ & Load Shedding I \\
\hline \multirow{3}{*}{ TS 3} & A & 99,8 & 99,8 & 97,1 & 94,6 & $\sqrt{ }$ & $\sqrt{ }$ & No Load Shedding \\
\hline & $\mathrm{B}$ & 99,1 & 99 & 95,5 & 91,8 & $\sqrt{ }$ & $\sqrt{ }$ & No Load Shedding \\
\hline & $\mathrm{C}$ & 98,7 & 98,8 & 97,9 & 97,5 & $\sqrt{ }$ & $\sqrt{ }$ & Load Shedding I \\
\hline \multirow{3}{*}{ TS 4} & A & 98,7 & 98,7 & 98,3 & 97,2 & $\sqrt{ }$ & $\sqrt{ }$ & Load Shedding II \\
\hline & $\mathrm{B}$ & 98 & 97,9 & 96,1 & 91,8 & $\sqrt{ }$ & $\sqrt{ }$ & Load Shedding II \\
\hline & $\mathrm{C}$ & 98,1 & 98,1 & 96,3 & 94 & $\sqrt{ }$ & $\sqrt{ }$ & Load Shedding II \\
\hline
\end{tabular}

2. Simulasi Kestabilan Transien Generator Lepas

Pada kasus motor starting yaitu motor akan beroperasi ketika sistem baru beroperasi selama 1 detik. Respon frekuensi, tegangan, dan sudut rotor akan diamati dengan mempertimbangkan referensi standar tegangan yang berdasar pada IEEE Std C37.106-2003. Motor yang akan beroperasi merupakan motor induksi tiga fasa dengan ID motor yaitu 260K101/102AM yang memiliki kapasitas daya 2700 HP dan 014K102ABCM yang memiliki kapasitas daya 2500 HP. Data yang diamati adalah respon frekuensi, tegangan dan sudut rotor ketika motor di-start.

Tabel 5. Hasil Simulasi Studi Kasus Motor Starting Menggunakan Load Shedding standar IEEE

\begin{tabular}{|c|c|c|c|c|c|c|c|c|}
\hline \multirow{2}{*}{\multicolumn{2}{|c|}{ Studi kasus }} & \multicolumn{2}{|c|}{$\begin{array}{c}\text { Frekuensi min } \\
(\%)\end{array}$} & \multicolumn{2}{|c|}{$\begin{array}{c}\text { Tegangan min } \\
(\%)\end{array}$} & \multicolumn{2}{|c|}{ kondisi } & \multirow[t]{2}{*}{ Load shedding } \\
\hline & & $33 \mathrm{kv}$ & $13,8 \mathrm{kv}$ & $33 \mathrm{kv}$ & $13,8 \mathrm{kv}$ & $\mathrm{f}$ & $\mathrm{V}$ & \\
\hline \multirow{2}{*}{ TS 11} & A & - & 99,9 & 96,7 & 96,4 & $\sqrt{1}$ & $\sqrt{1}$ & No Load Shedding \\
\hline & B & 98,7 & 98,7 & 95,9 & 97,6 & $\sqrt{ }$ & $\sqrt{ }$ & Load Shedding I \\
\hline
\end{tabular}

\section{KESIMPULAN}

Berdasarkan hasil yang diperoleh dari simulasi dan analisis pada Tugas Akhir ini, dapat diambil beberapa kesimpulan sebagai berikut:

1. Gangguan lepasnya generator pada sistem di beberapa bentuk operasi menyebabkan penurunan frekuensi pada bus $13,8 \mathrm{kv}$ maupun bus $33 \mathrm{kv}$. Sehingga perlu dilakukan penanganan untuk mengembalikan kestabilan sistem dengan melakukan pelepasan beban (load shedding)

2. Gangguan starting motor dilakukan pada pola operasi kemungkinan terburuk, sistem masih mampu mempertahankan kestabilannya saat motor starting $2700 \mathrm{HP}$ yang menggambarkan motor terbesar di plan Pertamina RU IV Cilacap terhubung ke sistem. Hal ini juga memberikan jaminan bahwa motor starting akan berhasil pada pola operasi yang lain.
3. Pelepasan beban (load shedding) yang dilakukan telah berhasil mengembalikan kestabilan sistem. Pelepasan beban yang digunakan mengacu pada standart ANSI/IEEE 3 langkah dengan pelepasan beban sebesar $10 \%$ untuk langkah 1 dan $15 \%$ untuk langkah 2.

4. Di beberapa operasi, Penggunaan frekuensi standart ANSI/IEEE dalam pelepasan beban (load shedding) mampu memperbaiki respon frekuensi lebih baik daripada standart frekuensi yang selama ini digunakan di PT. Pertamina RU IV Cilacap

\section{DAFTAR PUSTAKA}

[1] Marsudi, Djiteng, “Operasi Sistem Tenaga Listrik”, Yogyakarta : Graha Ilmu, 2006.

[2] IEEE/CIGRE Joint Task Force on Stability Terms and Definitions, "Definition and Classification of Power System 
JURNAL TEKNIK ITS Vol. 5, No. 1, (2016) ISSN: 2337-3539 (2301-9271 Print)

Stability", IEEE Transactions on Power System, Vol. 19, No. 2, May 2004

[3] ANSI/IEEE C37.106-1987, "IEEE Guide for Abnormal Frequency Protection for Power Generating Plants". 